\title{
Predicting Addiction Potential on the Basis of Early Traumatic Events, Dissociative Experiences, and Suicide Ideation
}

\author{
Seyedeh Fatemeh Sajadi ${ }^{1,2,}$; Zahra Hajjari ${ }^{3}$; Yadollah Zargar ${ }^{1}$; Mahnaz Mehrabizade \\ Honarmand ${ }^{1}$; Nasrin Arshadi ${ }^{1}$ \\ ${ }^{1}$ Department of Psychology, Shahid Chamran University, Ahvaz, IR Iran \\ ${ }_{3}^{2}$ Young Researchers and Elite Cub, Shiraz, IR Iran \\ ${ }^{3}$ Department of Preventive Medicine, Faculty of Medicine, Univesity of Malaya, Kuala Lumpur, Malaysia \\ *Corresponding author: Seyedeh Fatemeh Sajadi, Department of Psychology, Shahid Chamran University, Ahvaz, IR Iran. Tel: +98- 9173046244., E-mail: f-sajadi@mscstu.scu.ac.ir
}

Received: June 6, 2014; Revised: August 5, 2014; Accepted: August 16, 2014

\begin{abstract}
Background: There is a great deal of medical literature suggesting that substance use disorder is a serious clinical concern, affecting general population and associated with considerable economic, societal, and personal costs.

Objectives: This study sought to clarify the relationship between early trauma, dissociative experience, and suicide ideation as predictive factors of active and passive addiction potential(A/PAP) in high-school students.

Patients and Methods: Three hundred students with the mean age of $15.72 \mathrm{y}$ were selected via multistage random sampling. All participants were asked to complete Iranian addiction potential scale, early trauma inventory, dissociative experiences scale, and Beck's suicide ideation scale. Analyzing data was done using canonical correlation.

Results: Structural coefficients showed that the pattern of high scores in active/passive A/PAP correlates with the pattern of high scores in early trauma, dissociative experience and suicide ideation. The findings of the study showed that the combination of low active/passive A/ PAP can probably decrease the likelihood of early trauma, dissociative experience and suicide ideation.

Conclusions: Early trauma, dissociative experience, and suicide ideation can predict active/passive A/PAP and explain the considerable variance of survival index.
\end{abstract}

Keywords:Addictive; Cumulative Trauma Disorders; Suicidal Ideation; Dissociative Disorders

\section{Backgrounds}

Addiction potential (AP) is defined as the beliefs and attitudes of people about drugs, and the negative and positive outcomes of using them (1). Some theorists believe that addiction tendency is a physio-biological state, to be born with (2), meaning that addiction affects susceptible persons. Substance abuse (SA) is a complex disorder that incorporates multiple factors, including the psychological and/or biological predispositions of the individual (e.g. genetic, attitudinal, beliefs and personality factors, unconscious processes, gender, temperament), the developmental, social, economic, political environment in which the individual lives (i.e. situational characteristics), and the activity itself (i.e. structural characteristics) $(3,4)$. Also, SA motivation, have been cited to include a desire for positive emotions and affective experiences, coping with negative emotional states, and as a means of social reinforcement (5).

Many researchers investigating environmental influences on SA disorders, have asserted that the culture of school setting, family history, and traumatic experiences are powerful factors in determining $\mathrm{AP}(6)$. Other authors stated that childhood physical and sexual abuse, adult victimization and observing community violence are highly associated with SA (7-9). Based on Timko et al. (10) research, violence and abuse survivors are often involved in various coping behaviors; SA is also a way of overcoming negative psychological effects of past experiences. Because, trauma affects many levels of functioning aspects such as somatic, emotional, cognitive, behavioral, and characterlogical (11); those who experienced severe anxiety and depression states may be more vulnerable to alcohol and SA.

Clinical description of dissociation involves disturbance in memory integration, perception, trauma associating identity, and information processing $(12,13)$. Proposing "chemical dissociation" hypothesis may be helpful in this regard. It states that traumatized individuals with low capacity for psychological dissociation may try to create insensitivity and sedation states by abusing psychoactive substances, these substances are consumed to enter and reserve dissociative-like states (14). Dunn et al. (15) asserted that $41 \%$ of addicts score 15 and above in dissociative experiences scale. These individuals actually use drugs to manage side effects of trauma-caused dissociation. 
Suicidal ideation is defined by the Institute of Medicine in 2002 as thoughts, containing harming or killing oneself. Although suicidal ideation, suicidal attempts and suicides have similar correlations, there are considerable discontinuities among them (16). Indeed, suicidal ideation not only increases the risk of suicide and death caused by suicide (17), but also is a significant sign of mental health needs, risky sexual behaviors, SA and criminal manners (18). Comparing to general population, suicide rate due to alcohol and substance abusers is 10 and 14 times more, respectively (19). Depression is also associated with SA disorder, increasing suicidal behaviors consequently (20).

With research to date indicating that substance abusers are often screened for depression and anxiety, but less is done on trauma/dissociation of those with primary diagnosis of SA (21). Therefore, the main thrust of this study was to determine more effective variables of $\mathrm{AD}$ in high-school students. The results of this study could help mental health specialists to have better perception of the relationship between trauma, dissociation and suicidal ideation in predicting $\mathrm{AD}$ and consequently planning more appropriate treatment plans to reduce relapsing to SA.

\section{Objectives}

This study sought to clarify the relationship between early trauma, dissociative experience, and suicide ideation as predictive factors of active and passive addiction potential (AP) in high-school students.

\section{Materials and Methods}

This is a correlation-descriptive study, investigating the relationship between early trauma, dissociative experiences, and suicide ideation with AP among high-school students in Shiraz. The data obtained by questionnaires were analyzed with canonical correlation analysis using SPSS-18. Canonical correlation is similar to multiple regression analysis; a compound of predictor variables are applied to predict criterion variables. The difference lies in the number of criterion variables; in multiple regression, only one criterion variable exists while in canonical analysis, there are more than one variable (22).

\subsection{Participants}

Students from 4 regions in Shiraz, studying in the first to third grades of high school during the educational year of 2012-2013 (Iranian calendar: 1391-1392) were solicited to participate in the questionnaire surveys. The sample included 300 students (half males and half females) chosen by multistage random sampling. First, two girl's schools and two boy's schools were chosen randomly, then two classes in each school were selected by random and finally half of the students of each class were randomly chosen to answer the questionnaire. The age range of the participants was 14 to 18 years; with an average and standard deviation of $15.72 \pm 0.99$ years. Forty-five percent of the subjects were in the first grade, $41 \%$ in the second grade and $14 \%$ in the third grade of high school. The CGPA (Cumulative Grade Point Average) of students in sample was 17.14 , with standard deviation of 1.92 .

\subsection{Instruments}

Iranian addiction potential scale (IAPS) is a self-report measure, evaluating susceptibility or vulnerability toward SA in individuals abusing or not currently abusing. The measure contains 36 items, each scored on a fourpoint scale $(0=$ completely disagree to $3=$ completely agree) plus 5 lie detector statement reversely scored. IAPS assesses 2 factors: active potential ( 28 items), passive potential (9 items). The scale showed high internal consistency in prior research (Cronbach $\alpha>0.90$; Cronbach $\alpha$ for active potential $>0.91$; Cronbach $\alpha$ for passive potential > 0.75) (23). Zargar and Ghaffari (24) also reported good psychometric properties for total scale (Cronbach $\alpha>0.90 ; 0.91$ and 0.75 for active and passive potential, respectively). In the current study, Cronbach $\alpha$ for total scale, active and passive potential were reported to be $0.87,0.85$, and 0.70 , respectively.

Early Trauma Inventory (ETI) has 23 items, investigating traumas under the age of 18. Participants are asked to answer Yes/No to each item, scoring 1 for Yes and 0 for No. Total score varies from 0 to 23 . Adequate psychometric properties have been demonstrated for the scale in large samples; Mehrabizade et al. (25) reported Cronbach $\alpha<$ $0.89(n=120)$ and Cronbach $\alpha>0.91$ to $0.93(n=180)$. In the current study, the reliability was 0.71 using Cronbach $\alpha$ and 0.64 using half-split. To determine validity, it was correlated with a 10-score question, 0 (never) to 10 (always). Correlation coefficient was 0.50 ( $\mathrm{P}<0.001$ ).

Dissociative experience scale (DES) is a 28 -item self-report measure with a 10-point scale ranging from "never" (0\%), to "always" (100\%). Each item describes a kind of experience that the subjects may have had. Studies showed that a grade higher than 15 needs more investigation to diagnose dissociation. A score higher than 30 indicates high probability of dissociative disorders and PTSD, and scores over 40 express high probability of dissociative identity disorder (26). Factor analysis has revealed 3 factor structures which their subscales can be scored separately (27), including dissociative amnesia (e.g. finding new objects in your stuff that you do not remember buying), depersonalization and derealization (e.g. feeling that your body does not belong to you) and imaginative involvement (e.g. being in a familiar place but assigning as strange) (28). Criterion validity studies have been reported by Frischholz et al. (29). These findings indicate good concurrent and criterion related validity. Olsen and Beck (30) reported high internal consistency of DES with a Cronbach $\alpha$ of 0.7. In the current study Cronbach $\alpha$ was 0.92 . 
Sajadi SF et al.

Scale for Suicide Ideation (Beck et al. (31)) (SSI) is a 19item self-report questionnaire designed to measure severity of attitude, behaviors, and plans to complete suicide. It assesses death wish, active/inactive tendency to suicide, length and plentitude of suicidal thoughts, selfcontrol, and inhibitors and readiness to commit suicide (32). The items are scored on a 3-point scale from 0 to 2. The total score may vary from 0 to 38 , with higher scores indicating more intense levels of suicidal ideation (33). The SSI has demonstrated good psychometric properties for psychiatric outpatients (34). It is reported high internal consistency of SSI with Cronbach $\alpha$ of 0.89 . In the current sample Cronbach $\alpha$ was 0.9 (31).

\section{Results}

Descriptive statistics are reported for main study variables in Table 1.

As seen in Table 1, the mean (SD) scores obtained by the sample $(\mathrm{n}=300)$ on study variables were as follows: active AP, 18.07 (11.53); passive AP, 14.21 (4.92); early trauma,
5.54 (3.40); dissociative experiences, 30.233 (1.649); and suicidal ideation, 5.296 (6.412). To investigate the relationship between A/PAP and early trauma, dissociative experiences, and suicidal ideation in the total scale and sub-scales, a matrix for Pearson correlation coefficient was calculated. Table 2 presents the bivariate correlation between study variables.

According to Table 2, all variables have a positive correlation with each other; $\alpha$ coefficients range from 0.2 to 0.71 and all the correlations are significant at $\mathrm{P}<0.001$. These findings suggest that high scores of suicidal ideation and early trauma had the most correlation with high active AP scores. In the current study, in order to investigate variables relationship, canonical correlation analysis was used. Early trauma, dissociative experiences and suicidal ideation are considered as predictors of PAP and AAP to study the joint multivariate relationship between these two variables class. The results of multivariate test of significance for canonical correlation full model are presented in Table 3.

\begin{tabular}{lccc}
\hline Table 1. Means and Standard Deviation, and Ranges for Main Study Variables ${ }^{\mathrm{a}, \mathrm{b}}$ & & Max \\
\hline & \multicolumn{1}{c}{ Results } & Min & 74 \\
\hline AP & $36.48 \pm 12.54$ & 12 & 59 \\
\hline AAP & $18.07 \pm 11.53$ & 0 & 27 \\
PAP & $14.21 \pm 4.92$ & 1 & 17.00 \\
Early trauma & $5.550 \pm 3.420$ & 0 & 77 \\
Dissociative experiences & $30.23 \pm 16.49$ & 36 & 640 \\
Dissociative Amnesia & $1.93 \pm 143.46$ & 0 & 600 \\
$\begin{array}{l}\text { Depersonalization and } \\
\text { derealization }\end{array}$ & $1.23 \pm 110.78$ & 0 & 900 \\
Imaginative involvement & $3.74 \pm 182.24$ & 0 & 34 \\
\hline Suicidal ideation & $5.29 \pm 6.41$ & 0 & \\
\hline
\end{tabular}

b Abbreviations: APA, active addiction potential; PAP, passive addiction potential.

${ }^{\mathrm{a}}$ Data are presented as Mean \pm SD.

Table 2. Correlation Matrix for Research Variables $(n=300)$

\begin{tabular}{|c|c|c|c|c|c|c|c|}
\hline & 1 & 2 & 3 & 4 & 5 & 6 & 7 \\
\hline \multicolumn{8}{|l|}{ AP } \\
\hline AAP & - & - & - & - & - & - & - \\
\hline PAP & 0.55 & - & - & - & - & - & - \\
\hline Early trauma & 0.50 & 0.35 & - & - & - & - & - \\
\hline \multicolumn{8}{|l|}{ Dissociative experiences } \\
\hline Dissociative Amnesia & 0.30 & 0.34 & 0.27 & - & - & - & - \\
\hline $\begin{array}{l}\text { Depersonalization and } \\
\text { derealization }\end{array}$ & 0.34 & 0.36 & 0.29 & 0.68 & - & - & - \\
\hline Imaginative involvement & 0.29 & 0.38 & 0.28 & 0.71 & 0.66 & - & - \\
\hline Suicidal ideation & 0.51 & 0.40 & 0.39 & 0.26 & 0.30 & 0.17 & - \\
\hline
\end{tabular}


Wilks lambda $(\mathrm{P}<0.001)$ being statistically significant, explains a relationship between early trauma, dissociative experiences, suicidal ideation and A/PAP (Table 3 ). $\lambda$ is a sign of unexplained variance; consequently $1-\lambda$ is the full model effect size in $\mathrm{r} 2$ matrix. Accordingly, the effect size of three canonical correlation functions equals 1-0.54 $=0.46$. The effect size is the joint variance between 2 classes of variables that the full model can explain; therefore, the obtained model for this study explains $46 \%$ of variance between early trauma, dissociative experiences and suicidal ideation and A/PAP.

The number of functions obtained in the canonical analysis is equal to the number of variables in the smallest class (dependent or independent). Having two dependent variables, A/PAP, two functions are acquired (Table 4).In canonical correlation analysis, there is no convenient way to test significance level of functions separately. One way to investigate the issue is to consider the amount of variance that explains each function. As shown in Table 4 , canonical correlations square $\left(\mathrm{R}^{2} \mathrm{C}\right)$ of functions are 0.431 and 0.040 , respectively. Regarding findings by Sherry et al. (35), functions explaining less than $10 \%$ variance are laid away and are not interpreted, then only the first function explaining $43 \%$ of joint variance is accepted and other functions disregarded.

In addition to the mentioned method, researchers can test the significance level by dimension reduction analysis (Table 5).

Tests of significance results of cumulative effect of functions 1 and 2 are presented in Table 5, first row. The test checks if the structure of functions is significant or not. As it was mentioned, cumulative effect of functions 1 and 2 (full model) is statistically significant $(\mathrm{P}<0.001)$, but the 2 to 2 cumulative effect is not significant. In other words, only first function explains a significant amount of joint variance between two classes of variables.

Results, so far, indicate that there is a significant relationship between 2 classes of variables and only the first function denotes a significant variance. To find out the role of each variable in the functions, standard and structural coefficients of variables are considered. Table 6 presents standard coefficients, structural coefficients and square structural coefficient for dependent and independent variables in the first canonical function.

Table 3. Multivariate Test of Significance for Canonical Correlation Full Model

\begin{tabular}{lccccc}
\hline & Value & F & DF1 & DF2 & $P$ Value \\
\hline Pillais & 0.4714 & 18.13 & 10 & 588 & $<0.001$ \\
Wilks & 0.5459 & 23.35 & 10 & 586 & $<0.001$ \\
Hotellings & 0.7999 & 20.70 & 10 & 584 & $<0.001$ \\
\hline
\end{tabular}

Table 4. Functions Obtained From Canonical Correlation Analysis

\begin{tabular}{lccccc}
\hline Root Number & Eigenvalue & Percent & Cumulative, $\%$ & Canonical Correlation & Square Correlation \\
\hline $\mathbf{1}$ & 0.758 & 94.7 & 97.7 & 0.656 & 0.431 \\
$\mathbf{2}$ & 0.041 & 5.24 & 100 & 0.200 & 0.040 \\
\hline
\end{tabular}

Table 5. Results for Dimension Reduction Analysis of Canonical Functions

\begin{tabular}{lccccc}
\hline Roots & Wilks L & F & DF1 & DF2 & $P$ Value \\
\hline $\mathbf{1 - 2}$ & 0.545 & 20.70 & 10 & 586 & $<0.001$ \\
$\mathbf{2 - 2}$ & 0.959 & 3.08 & 4 & 294 & 0.017 \\
\hline
\end{tabular}

Table 6. Standard, Structural and Square Structural Coefficients of Research Variables

\begin{tabular}{lccc}
\hline & Standard Coefficient & Structural Coefficient & Square Structural Coefficient \\
\hline AAP & 0.735 & 0.946 & 0.894 \\
\hline PAP & 0.384 & 0.789 & 0.622 \\
$\mathbf{R}^{\mathbf{2} C}$ & & 0.43 & 0.592 \\
Early trauma & 0.442 & 0.770 & 0.300 \\
Dissociative amnesia & 0.035 & 0.548 & 0.350 \\
$\begin{array}{l}\text { Depersonalization and } \\
\text { derealization }\end{array}$ & 0.123 & 0.592 & 0.302 \\
Imaginative involvement & 0.222 & 0.550 & 0.669 \\
\hline Suicidal Ideation & 0.548 & 0.818 & \\
\hline
\end{tabular}




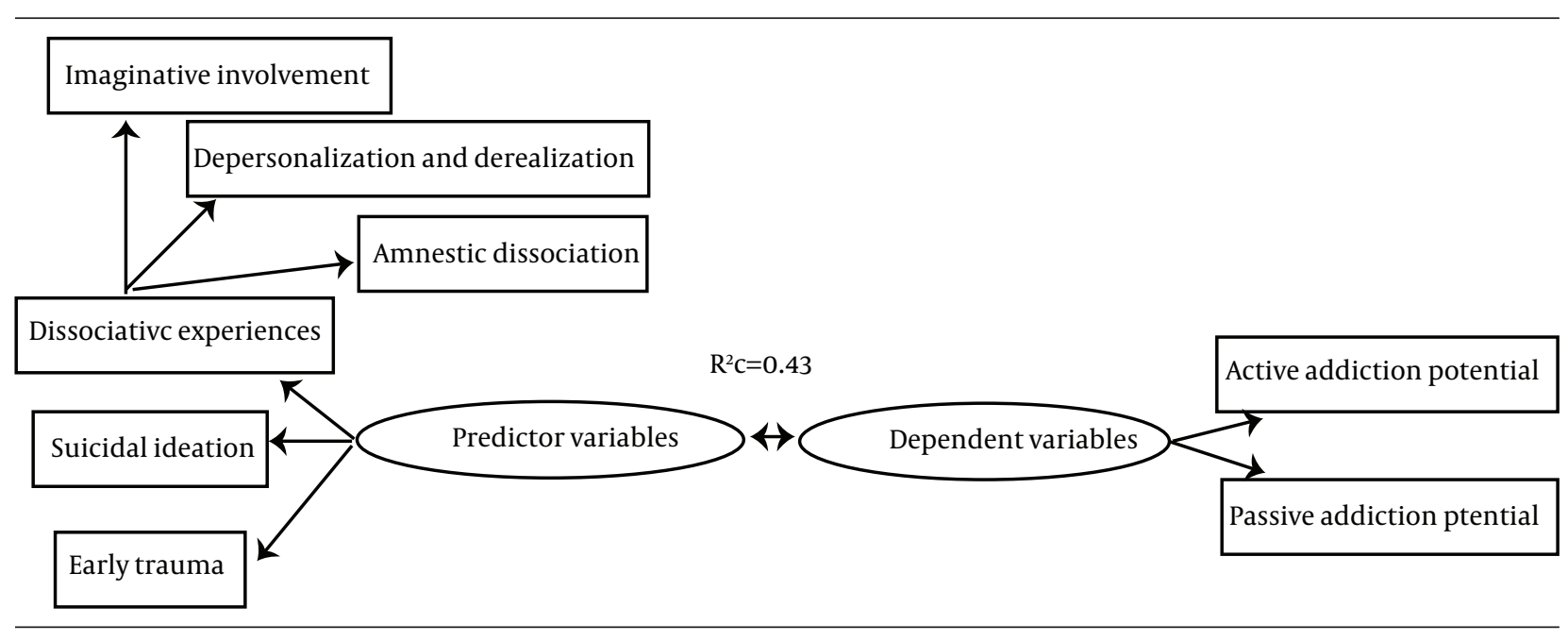

Figure 1. Presents Conceptual Relationship Between Dependent and Predictor Variables

Following Alpert and Peterson, only variables with minimum structural coefficients of 0.3 are interpreted. Therefore, data presented in Table 6 shows that in the first function, suicidal ideation (structural coefficient $[S C]=0.81$, early trauma $(S C=0.77)$, depersonalization and derealization ( $\mathrm{SC}=0.59$ ), imaginative involvement $(\mathrm{SC}=0.55)$, and dissociative amnesia $(\mathrm{SC}=0.54)$ have respectively more important roles in linear structure of predictor variables. Regarding dependent variables, AAP $(\mathrm{SC}=0.94)$ and $\mathrm{PAP}(\mathrm{SC}=0.78)$ both affect linear structure of dependent variables.

More specifically, active and passive AP are predicted by early trauma, dissociative experiences and suicidal ideation. Also, canonical $R$ square coefficient $\left(R^{2} C\right)$ is $43 \%$ that determines amount of joint variance between two canonical classes of independent and dependent variables. Furthermore, based on standard coefficients presented in Table 6, for each one standard deviation increment in active AP, the first canonical function score increases as 0.73 , and with a unit increase in standard deviation of passive $\mathrm{AP}$, first function score increases to 0.384 . For each unit increase in standard deviation of early trauma, dissociative amnesia, depersonalization and derealization and imaginative involvement, the score of first canonical function increases to $0.44,0.03,0.12$ and 0.22 . Finally, with each unit increase in suicidal ideation standard deviation, canonical function score increases up to 0.54 (Figure 1).

\section{Discussion}

To our knowledge, this study is the first to investigate the role of early trauma, dissociative experiences (dissociative amnesia, depersonalization and derealization, and imaginative involvement) and suicidal ideation in predicting active and passive AP in high-school students. Taken together, our findings demonstrated that the conceptual relationship between dependent and predictor variables is possible. Canonical analysis led to the formation of a statistically meaningful function. These findings are explained based on cross loading, the best method to interpret canonical functions. It suggests that a pattern of high scores in early trauma, dissociative experiences and suicidal ideation are correlated with a pattern of high scores of active and passive AP.

In line with Min et al. (7), Perron et al. (8), and Zinzow et al. (9), we demonstrated that AP is associated with early trauma. Such a finding fits well with Timko et al. (10) view, for they believe that SA is an effort to cope with negative psychological effect of abuse and violence in traumatized individuals. Indeed, distress resulting from traumatic experiences enforces individuals to find ways or behaviors to reduce these negative states, behaviors such as drinking alcohol or SA(36).

Like Najavits and Walsh (36), Dunn et al. (15), Putnam (37), and Ursano et al. (38) studies, our findings highlight the association between AP and dissociative experiences. Results of the studies reported that DES scores for drug abusers equal to 19.2 (39), 22.9 (40), 24.5 (41), and 29 (2). To clarify the findings, it is said that SA is a form of "chemical dissociation" to neutralize trauma's symptoms (42). In this case, SA is considered as a form of dissociation. This viewpoint explains how SA acts as a medium to avoid emotions and memories of trauma (43). However, it is also known that SA may be aiming to access memories and negative emotions related to trauma not to make distance (44).

We also found supporting evidence for an association between suicidal ideation and AP (19-24). We extend their findings by demonstrating this to be the case in adolescents aged (14-18 years old) too. An important issue is that one protective factor against suicide is social protection (45). SA is positively correlated with the low levels of social protection or high levels of social isolation (46), which has been implicated in suicide risk (47).

Finally, as previously mentioned, the results indicated that a linear structure of psychological variables explaining active/passive AP in high-school students are early 
trauma, dissociative experiences, and suicidal ideation, respectively. Despite these promising findings, there are several limitations to the current study, which may have also affected our findings. First, our sample, due to methodological considerations, was composed mostly of 14-18 years old students. It is avisable to perform more investigations on clinical samples, larger groups, and other age groups to elucidate actual trauma prevalence, dissociative experiences, and suicidal ideation in those with SAD to attain exact and generalizable data. Second, our sample was not a high-risk sample; however, it is representative of the wider normal population. As well, further studies should also pay more careful attention to the demographic variables such as sex, social and economic class; it may extend generalizability of the findings. By empirically describing the causal pathways by which severe conduct problems are established in early adults, we are better able to design more individualized interventions for youths with emerging substance use disorder.

\section{Acknowledgements}

The authors are grateful to all students who participated in this study. Data collection for the study took place within the four regions in Shiraz, Iran.

\section{Authors' Contributions}

Seyede Fatemeh Sajadi: analysis and interpretation of data, drafting of the manuscript, statistical analysis and study supervision; Zahra Hajjari: acquisition of data; Nasrin Arshadi: administrative, technical, and material support; Yadolla Zargar: study concept and design; and Mahnaz Mehrabizade Honarmand: critical revision of the manuscript for important intellectual content.

\section{References}

1. Bakhshi Bojed F, Nikmanesh Z. Role of early maladaptive schemas on addiction potential in youth. Int J High Risk Behav Addict. 2013;2(2):72-6.

2. Tomer JF. Addictions are not rational: a socio-economic model of addictive behavior. J Socio Econ. 2001;30(3):243-61.

3. Griffiths MD. Early Maladaptive Schemas in Development of Addictive Disorders as Parts of the Complex Addiction Jigsaw. Int J High Risk Behav Addict. 2014;3(3).

4. Jafari E, Ahmadi M, Mohammadzadeh A, Najafi M. The Effectiveness of Lifestyle Training in Relapse Prevention and Resiliency Enhancement for People with Substance Dependency. Int J High Risk Behav Addict. 2012;1(1):34-8.

5. Read JP, Wood MD, Kahler CW, Maddock JE, Palfai TP. Examining the role of drinking motives in college student alcohol use and problems. Psychol Addict Behav. 2003;17(1):13-23.

6. Calmes SA. The Relationship between Adverse Childhood Events, Resilience, and Substance Dependence among a College Freshman Population. : University of Toledo; 2012.

7. Min M, Farkas K, Minnes S, Singer LT. Impact of childhood abuse and neglect on substance abuse and psychological distress in adulthood. J Trauma Stress. 2007;20(5):833-44.

8. Perron BE, Gotham HJ, Cho D. Victimization among AfricanAmerican adolescents in substance abuse treatment. J Psychoactive Drugs. 2008;40(1):67-75.

9. Zinzow HM, Ruggiero KJ, Hanson RF, Smith DW, Saunders BE,
Kilpatrick DG. Witnessed community and parental violence in relation to substance use and delinquency in a national sample of adolescents. J Trauma Stress. 2009;22(6):525-33.

10. Timko C, Sutkowi A, Pavao J, Kimerling R. Women's childhood and adult adverse experiences, mental health, and binge drinking: The California Women's Health Survey. Subst Abuse Treat Prev Policy. 2008;3(1):15.

11. Kianpoor M, Bakhshani NM. Trauma, dissociation, and high-risk behaviors. Int J High Risk Behav Addict. 2012;1(1):9-13.

12. American Psychiatric Association. Diagnostic and statistical manual of mental disorders.Washington: American Psychiatric Association; 1994.

13. Bower GH, Sivers H. Cognitive impact of traumatic events. Dev Psychopathol.1998;10(4):625-53.

14. Langeland W, Draijer N, van den Brink W. Trauma and dissociation in treatment-seeking alcoholics: towards a resolution of inconsistent findings. Compr Psychiatry. 2002;43(3):195-203.

15. Dunn GE, Ryan JJ, Paolo AM, Van Fleet JN. Comorbidity of dissociative disorders among patients with substance use disorders. Psychiatr Serv. 1995;46(2):153-6.

16. Roy A. Characteristics of opiate dependent patients who attempt suicide. J Clin Psychiatry. 2002;63(5):403-7.

17. Yoder KA. Comparing suicide attempters, suicide ideators, and nonsuicidal homeless and runaway adolescents. Suicide Life Threat Behav.1999;29(1):25-36.

18. ten Have M, de Graaf R, van Dorsselaer S, Verdurmen J, van 't Land $\mathrm{H}$, Vollebergh W, et al. Incidence and course of suicidal ideation and suicide attempts in the general population. Can J Psychiatry. 2009;54(12):824-33.

19. Wilcox HC, Conner KR, Caine ED. Association of alcohol and drug use disorders and completed suicide: an empirical review of cohort studies. Drug Alcohol Depend. 2004;76 Suppl:S11-9.

20. Conner KR, Hesselbrock VM, Meldrum SC, Schuckit MA, Bucholz KK, Gamble SA, et al. Transitions to, and correlates of, suicidal ideation, plans, and unplanned and planned suicide attempts among 3,729 men and women with alcohol dependence. J Stud Alcohol Drugs. 2007;68(5):654-62.

21. McDowell DM, Levin FR, Nunes EV. Dissociative identity disorder and substance abuse: the forgotten relationship. J Psychoactive Drugs. 1999;31(1):71-83.

22. Delavar A. Theory and Research in the Humanities and Social Sciences.Tehran: Roshd; 1997.

23. Zargar Y. Developing Iranian addiction potential scale. Second congress of Iran psychology association. IR Iran.

24. Zargar Y, Ghaffari M. Simple and multiple relationships between big-five personality dimensions and addiction in university students. Iran J Public Health. 2009;38(3):113-7.

25. Mehrabizade M, Zargar Y, Arshadi N, Ahmadi V, Palahang $\mathrm{H}$ Designing and testing a model of some antecedents and precedents of narcisstic personality in university students. $J$ Mod Psychol Stud. 2011;25.

26. Kianpoor M, Ghanizadeh A, Badiei H. The relationship between dissociative experiences and the success of treatment through abstinence from opioid-use disorders. ZJRMS. 2012;14(10):56-60.

27. Ross CA, Joshi S, Currie R. Dissociative experiences in the general population: a factor analysis. Hosp Community Psychiatry. 1991;42(3):297-301.

28. Renard SB, Pijnenborg M, Lysaker PH. Dissociation and social cognition in schizophrenia spectrum disorder. Schizophr Res. 2012;137(1-3):219-23.

29. Frischholz EJ, Braun BG, Sachs RG, Schwartz DR, Lewis J, Shaeffer D, et al. Construct validity of the Dissociative Experiences Scale: II. Its relationship to hypnotizability. Am J Clin Hypn. 1992;35(2):145-52.

30. Olsen SA, Beck JG. The effects of dissociation on information processing for analogue trauma and neutral stimuli: a laboratory study. J Anxiety Disord. 2012;26(1):225-32.

31. Beck AT, Kovacs M, Weissman A. Assessment of suicidal intention: the Scale for Suicide Ideation. J Consult Clin Psychol. 1979;47(2):343-52.

32. Zhang J, Brown GK. Psychometric properties of the scale for suicide ideation in China. Arch Suicide Res. 2007;11(2):203-10. 
33. Witte TK, Joiner TE, Jr, Brown GK, Beck AT, Beckman A, Duberstein $\mathrm{P}$, et al. Factors of suicide ideation and their relation to clinical and other indicators in older adults. J Affect Disord. 2006;94(13):165-72.

34. Beck AT, Brown GK, Steer RA. Psychometric characteristics of the Scale for Suicide Ideation with psychiatric outpatients. Behav Res Ther. 1997;35(11):1039-46.

35. Sherry A, Henson RK. Conducting and interpreting canonical correlation analysis in personality research: a user-friendly primer. J Pers Assess. 2005;84(1):37-48.

36. Najavits LM, Walsh M. Dissociation, PTSD, and substance abuse: an empirical study. J Trauma Dissociation. 2012;13(1):115-26.

37. Putnam FW. Dissociative disorders in children: behavioral profiles and problems. Child Abuse Negl.1993;17(1):39-45.

38. Ursano RJ, Fullerton CS, Weisaeth L, Raphael B. Individua and community responses to disasters, Textbook of disaster psychiatry.Cambridge: Cambridge University Press; 2007.

39. Van Den Bosch L, Verheul R, Langeland W, Van Den Brink W. Trauma, dissociation, and posttraumatic stress disorder in female borderline patients with and without substance abuse problems. Aust N Z J Psychiatry. 2003;37(5):549-55.
40. Evren C, Sar V, Karadag F, Tamar Gurol D, Karagoz M. Dissociative disorders among alcohol-dependent inpatients. Psychiatry Res. 2007;152(2-3):233-41.

41. Karadag F, Sar V, Tamar-Gurol D, Evren C, Karagoz M, Erkiran M. Dissociative disorders among inpatients with drug or alcohol dependency. J Clin Psychiatry. 2005;66(10):1247-53.

42. Roesler TA, Dafler CE. Chemical dissociation in adults sexually victimized as children: alcohol and drug use in adult survivors. $J$ Subst Abuse Treat.1993;10(6):537-43.

43. Somer E, Altus L, Ginzburg K. Dissociative psychopathology among opioid use disorder patients: exploring the "chemical dissociation" hypothesis. Compr Psychiatry. 2010;51(4):419-25.

44. Najavits LM. Seeking safety: A treatment manual for PTSD and substance abuse.New York: Guilford; 2002.

45. Arria AM, O'Grady KE, Caldeira KM, Vincent KB, Wilcox HC, Wish ED. Suicide ideation among college students: a multivariate analysis. Arch Suicide Res. 2009;13(3):230-46.

46. Kendall RE. Alcohol and suicide. Subst Alcohol Actions Misuse. 1983;4(2-3):121-7.

47. Joiner T. Why people die by suicide.Cambridge: Harvard University Press; 2005. 